\title{
Proposed synchronization circuits connecting wind driven DFIG to the public grid
}

\author{
M. Hussein Agamy, Fathe M. Allythi, Adel S. Nada \\ Faculty of Engineering, Department of Electrical Engineering, Al-Azhar University, Cairo, Egypt
}

\begin{tabular}{l} 
Article Info \\
\hline Article history: \\
Received Sep 2, 2020 \\
Revised Jan 21, 2021 \\
Accepted Feb 1, 2021 \\
\hline
\end{tabular}

Keywords:

Arduino

Doubly fed induction generator

Turbine synchronization

Wind energy

\begin{abstract}
This paper presents a tested proposal scheme to connect a DFIG driven by a wind turbine to the public grid. This scheme was implemented to drive an automatic transfer switch (ATS). Control of the phase sequence, phase difference, and the frequency of the injected power are achieved using these proposed control circuits. These circuits are practically implemented and laboratory tested. The system allows monitoring the rated frequency, synchronization, and fundamental magnitude. Simulation software such as Multi Sim and Proteus are used for system validation and compatibility. The implemented circuits are used for re-scaling the grid voltage to the logic level for real time comparison and calculations. In addition to the feature of data monitoring, the system can also log these data for the system debugging purposes. The system can be considered as a real time control where the measurements and the correction are made in few milliseconds (fractions of the fundamental cycle). The lower cost control circuits are implemented using an Arduino kit in addition to a discrete digital component. The simulation and experimental results are in satisfactory agreement showing the most salient features of this system.
\end{abstract}

This is an open access article under the CC BY-SA license.

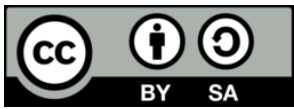

\author{
Corresponding Author: \\ Mohamed Hussein Agamy \\ Department of Electrical Engineering \\ Al Azhar University \\ Nasser City, Cairo, Egypt \\ Email: Eng_mo.hussein@yahoo.com
}

\section{INTRODUCTION}

Wind energy is one of the rapid promising growth renewable energy in the world. This energy is inexhaustible and clean, and it does not create greenhouse gases [1]. The wind turbines commonly use doubly fed induction generators (DFIG) because of their advantages such as they can maintain the amplitude and frequency of their output voltages at a constant value, no matter the speed of the wind or the speed of turbine rotor [2]-[4]. The DFIG has two outputs: one from stator and the other from rotor. The main advantage of DFIG is that the rotor side output represents only (20-25\%) of the total system power [5]-[7], so the power electronics components handle only with a fraction of the generator power. This reduces the acquisition costs and the losses in power electronics devices. The quality of the generated power is also improved in terms of harmonic and voltage fluctuations [8]. Generally, the stator output is connected directly to the network, but the rotor output is connected via a back-to-back converter [9]-[12]. The back-to-back converter consists of two converters, rotor-side converter (RSC) and Grid-side converter (GSC). Between the two converters a dc link capacitor is placed, as energy storage, in order to reduce voltage variations (or ripple) in the dc-link. The RSC is used to control the torque or the speed of the DFIG and also the power factor at the stator terminals, while the GSC is used for keeping the dc-link voltage constant [13]. Many of papers discuss the 
synchronization of DFIG and provide many solutions to connect it with the Grid [14]-[18]. Indeed, in spite of these sufficient solutions, they are not efficient, not easy to implement and not the lower cost ones. This paper proposes controlling and monitoring as well as storing circuits for connecting the DFIG with the grid sides automatically

The ATS power circuit has three $3 \Phi$-switches as shown in Figure 1; switch Sw1 is used for the Rotor grid connection, Sw2 will be used for connecting the rotor with a back to back converter and Switch Sw3 for the Stator grid directly connection.

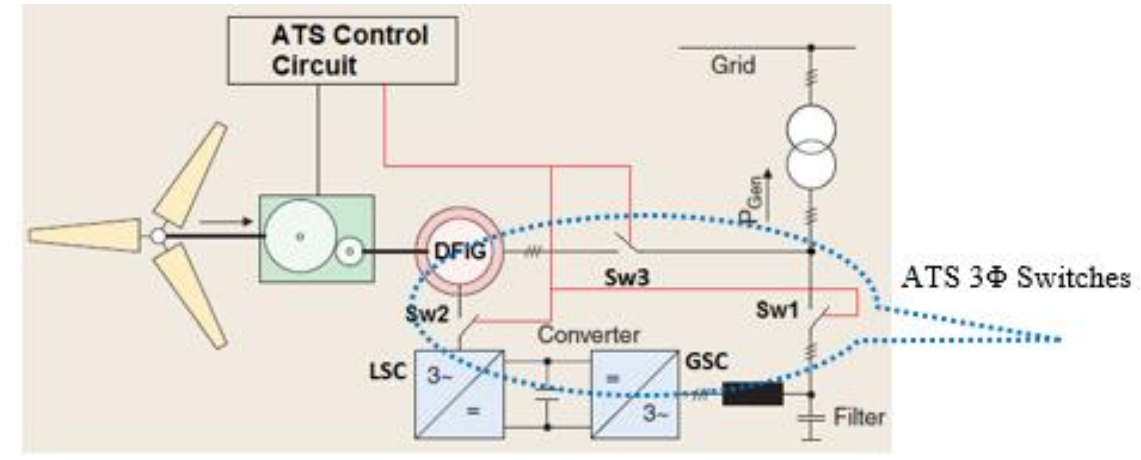

Figure 1. Connection of DFIG to the grid using ATS

\section{ATS CONTROL CIRCUITS}

The basic principle of DFIG driven by a wind turbine is that the rotating speed must be over than the generator cut off speed and during the synchronization process. The blade pitch angle controller adjusts the speed closely to the synchronous speed in order to adjust the stator frequency to be the same with the the grid frequency. The results of some related papers found that the induced stator voltage must be equal to the grid voltage before the synchronization and this can be achieved by adjusting the rotor flux [19-23]. The ATS monitors the output of DFIG and controls the switches (ON-OFF). Synchronization system configured of a controller in addition to four different stages; 1) Phase sequence detector, 2) Digital frequency meter, 3) Voltage magnitude comparator, 4) Phase difference detector. The controller configured of a lower cost Arduino kit accompanied with discrete logic circuits.

\subsection{Phase Sequence Detction}

The first stage in the control circuit is a phase sequence detection by using the phase sequence protection relay as shown in Figure.2, this is for guaranteeing the system correct sequence before starting to be connected. It is sufficient enough that the R-S-T sequence of the DFIG output windings will be the same with the Grid sequence for the first time of wind speed cut-in.
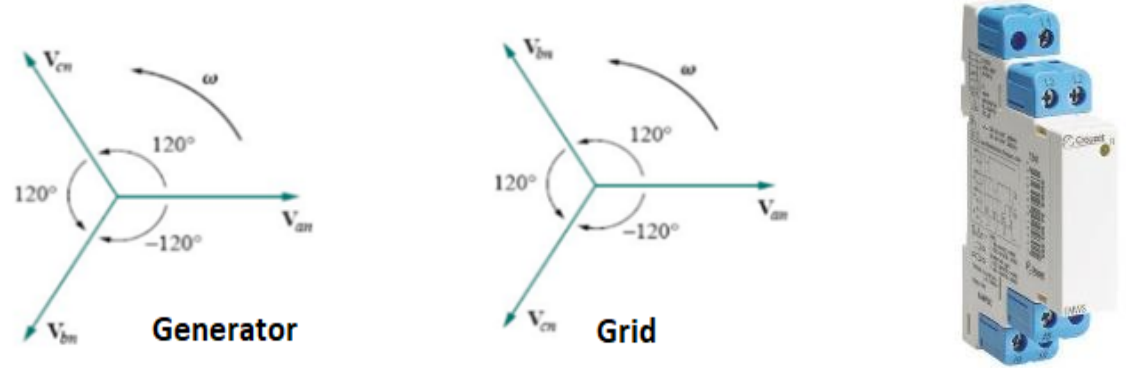

Figure 2. Phase sequence protection relay

\subsection{Voltage Magnitude Compartor}

The voltage magnitude for DFIG and the Grid must be the same. The ATS control circuit compares the DFIG voltage magnitude with the Grid voltage using difference amplifier. One of the comparator inputs 
is driven by the output of grid lower scale AC to DC converter. This input is the reference voltage of the comparator. The second comparator input is supplied by the DFIG AC to DC converter. The output status leads the Arduino circuit to adjust the Rotor back-to-back converter to ensure satisfactory flux level of the DFIG as shown in Figure 3.

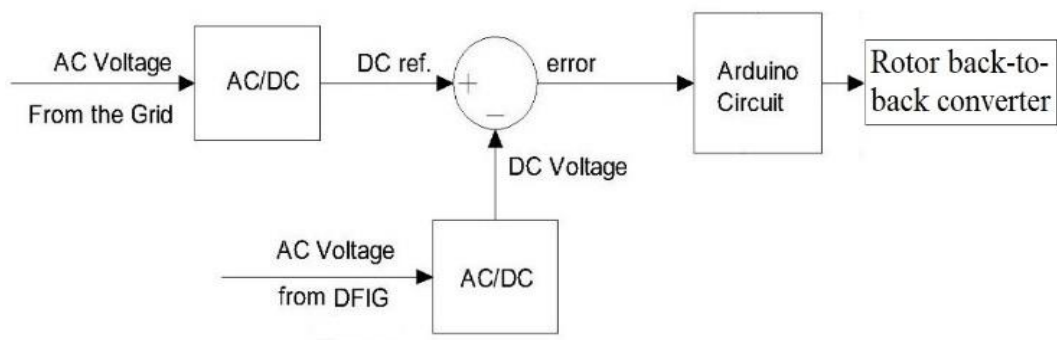

Figure 3. Schematic diagram for voltage magnitude comparator

\subsection{Frequency Metering}

The third stage in ATS control circuit is to measure the frequency of the DFIG to insure that it is the same with the Grid frequency. In Egypt the network frequency is $50 \mathrm{~Hz}$, so the measured frequency from the generator will be compared with $50 \mathrm{~Hz}$ and the output error will be used to support the Arduino for controlling the mechanical driver or the blade pitch angle to ensure proper speed of the driver as shown in Figure 4.

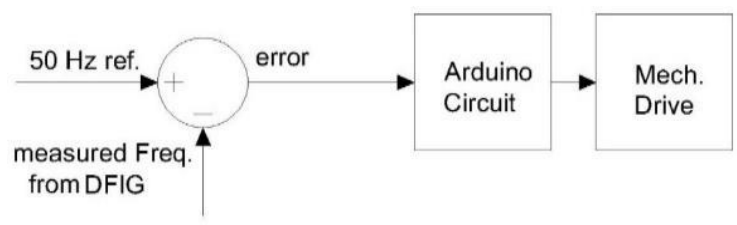

Figure 4. Schematic diagram for frequency circuit

\subsection{PHASE DIFFERENCE DETECTOR}

The fourth stage in the ATS control circuit is to check the phase angle between the DFIG voltage outputs and the network and to choose the appropriate moment for the connection between them. The system is designed to run this stage after making sure that the previous three steps have been completed. A multiplier IC (AD633j) is used for the phase difference determination. This multiplier output will be obtained as a result of both multiplying the Grid phase angle $\left(\omega t-\theta_{q}\right)$ and the DFIG phase angle $\left(\omega t-\theta_{d}\right)$ while the output of (AD633j) multiplier $V$ (in voltage) can be driven according to (1) [24, 25]:

$$
V_{0}=\frac{\left.\left(X_{1}-X_{2}\right) *(Y 1-Y 2]\right)}{10 \mathrm{~V}}+Z
$$

According to the implemented configuration, $Z, X_{2}$, and $Y_{2}$ are zeros, then the (1) can be rewritten as (2):

$$
V_{0}=\frac{1}{10}\left(\sin \left(\omega t-\theta_{g}\right) * \sin \left(\omega t-\theta_{d}\right)=-\frac{1}{20}\left[\cos \left(2 \omega t-\theta_{g}-\theta_{g}\right)-\cos \left(\theta_{d}-\theta_{g}\right)\right]\right)
$$

where $\boldsymbol{V}_{\boldsymbol{o}}$ is the output voltage corresponding to the phase difference. Referring to (2), the output of multiplier has two parts:

$$
\boldsymbol{V o} \text { (first part): }=-\frac{1}{20} \cos \left(2 \omega t-\theta_{g}-\theta_{d}\right)
$$

This part is cosine wave and the frequency for this wave is double the fundamental frequency, so to eliminate this wave we use a low pass filter for rejecting double fundamental frequency. One can calculate the value of the filter resistance and capacitor using the (4):

Proposed synchronization circuits connecting wind driven DFIG to the public grid (M. Hussein Agamy) 


$$
f=\frac{1}{2 \pi R C}
$$

where:

$f=$ double frequency in our case $=2 * 50=100 \mathrm{~Hz}$

So, the output

$$
V_{\boldsymbol{o}}(\text { second part })(\mathbf{V})=\frac{1}{20} \cos \left(\theta_{d}-\theta_{g}\right)
$$

shows that the output is a cosine function can be considered a linear in the range of $90 \geq\left(\theta_{d}-\theta_{q}\right) \geq-90$ where it is time independent and then $-0.05 \leq \frac{1}{2} \cos \left(\theta_{d}-\theta_{g}\right) \leq 0.05$ is the dynamic range of the phase detector. However, the DC value varies from -0.05 to 0.05 , the controller takes the action at $\theta_{d}=\theta_{q}$ and the multiplier output will be zero. As an overall, the ATS controller starts to detect the phase sequence, magnitude of the voltage the frequency and DFIG phase angle. The controller observes the zero output of the multiplier to connect between both the DFIG and the grid sides.

\section{EXPERIMENTAL WORK}

The experimental work in this research focuses on the ATS control circuits that are used for monitor and synchronize the DFIG output with the Grid. We have three main circuits; one for matching the voltages magnitudes, the second for synchronizing the frequency and the third for phase angle detection. As shown in Figure 5, the DFIG is driven by DC motor which is powered by variable DC supply to simulate wind turbine. The output of DFIG is interfaced with the ATS contactors for switching to the Grid transformer. The control circuits are powered by DC power supply.

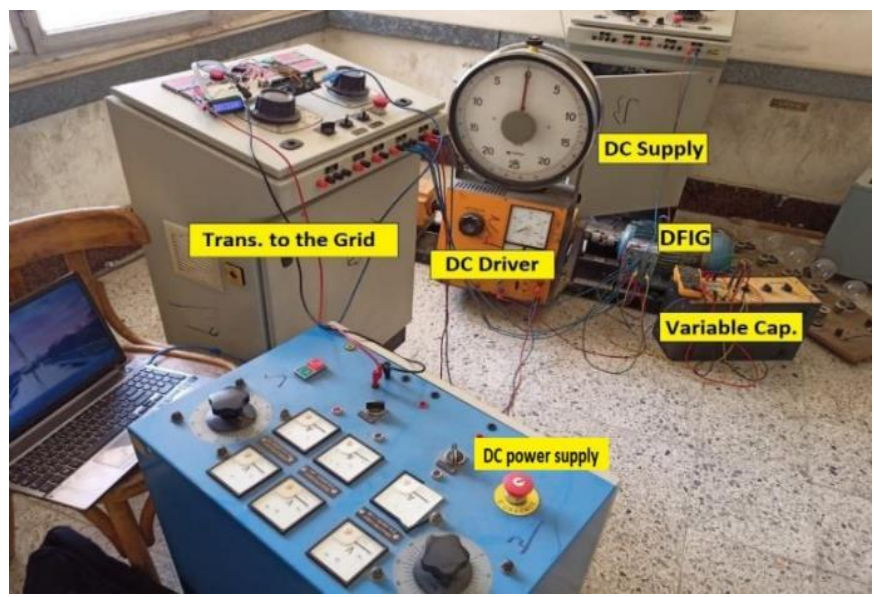

Figure 5. Image during one of laboratory tests

\subsection{Voltage magnitude circuit}

Resistors $\left(\mathrm{R}_{1}-\mathrm{R}_{4}\right),\left(\mathrm{R}_{2}-\mathrm{R}_{11}-\mathrm{R}_{3}\right)$ and $\left(\mathrm{R}_{2}-\mathrm{R}_{11}-\mathrm{R}_{3}\right)$, are re-scale stages for interfacing the power and logic sides. Moreover, a voltage readable to logic ICs can be implemented using either a step down transforms or resistors divider to reduce the voltage to approximately 5VDC. The system has two voltage supplies; one from the Grid and we use it as a reference voltage and the other from the DFIG. Diode bridges are used for converting the AC voltage to DC voltage, and two IC comparators (LM741) are used to compare between reference voltage from the Grid $\left(\mathrm{V}_{2}\right)$ and measured voltage from DFIG $\left(\mathrm{V}_{1}\right)$ as shown in Figure 6. This circuit allows voltage difference that is only 2VAC upper than the Grid voltage magnitude. This means that the output from the AND gate $(74 \mathrm{LS} 08 \mathrm{~N})$ is only available in the range of $220 \leq \mathrm{V}_{1} \leq 222 \mathrm{~V}$. The output of the AND gate is connected to Arduino circuit as indication that the voltage magnitude for DFIG and the Grid are equals. 


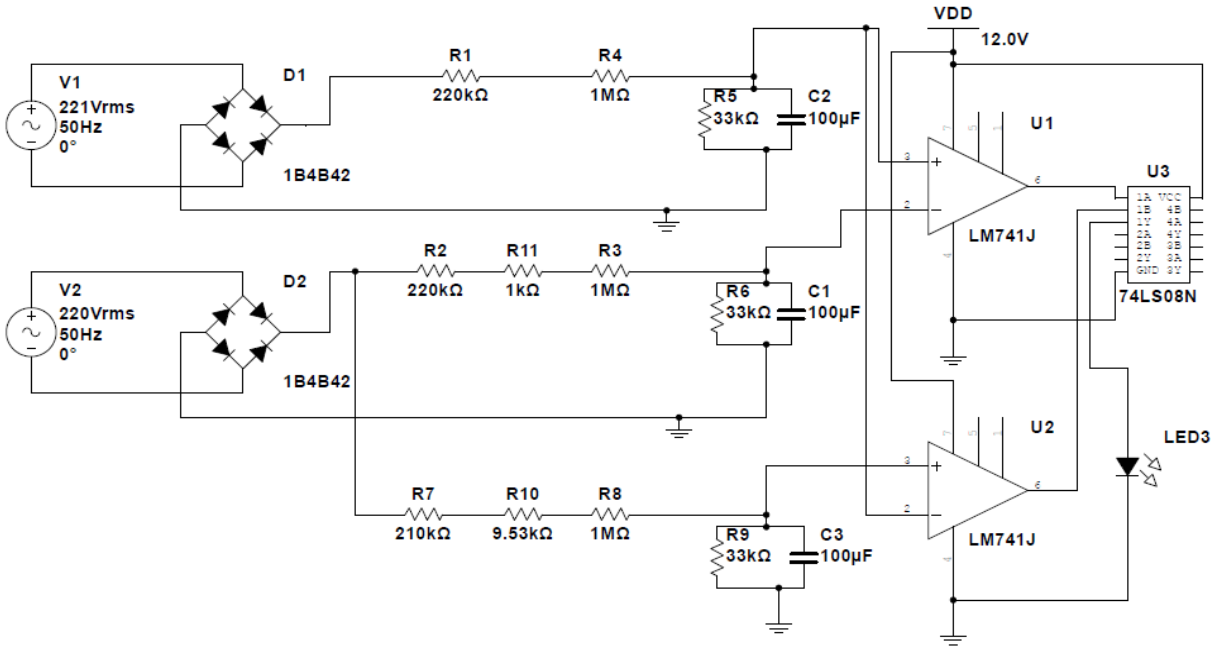

Figure 6. Circuit to compare voltage magnitude

\subsection{Frequency meter circuit}

The frequency meter circuit is made by Arduino (Mega Kit). The circuit shown in Figure 7 can read frequencies approximately from $35 \mathrm{~Hz}$ to $100 \mathrm{KHz}$. In this case, it allows frequencies from $49 \mathrm{~Hz}$ to $51 \mathrm{~Hz}$. The Arduino read the DFIG frequency and display it on the LCD screen. The Arduino works as AND gate to make sure that the phase sequence is OK and voltage magnitude are the same and when range of the DFIG reading frequency is from $49 \mathrm{~Hz}$ to $51 \mathrm{~Hz}$, the Arduino waits for the final circuit (phase angle circuit) to take the action to connect to the Grid.

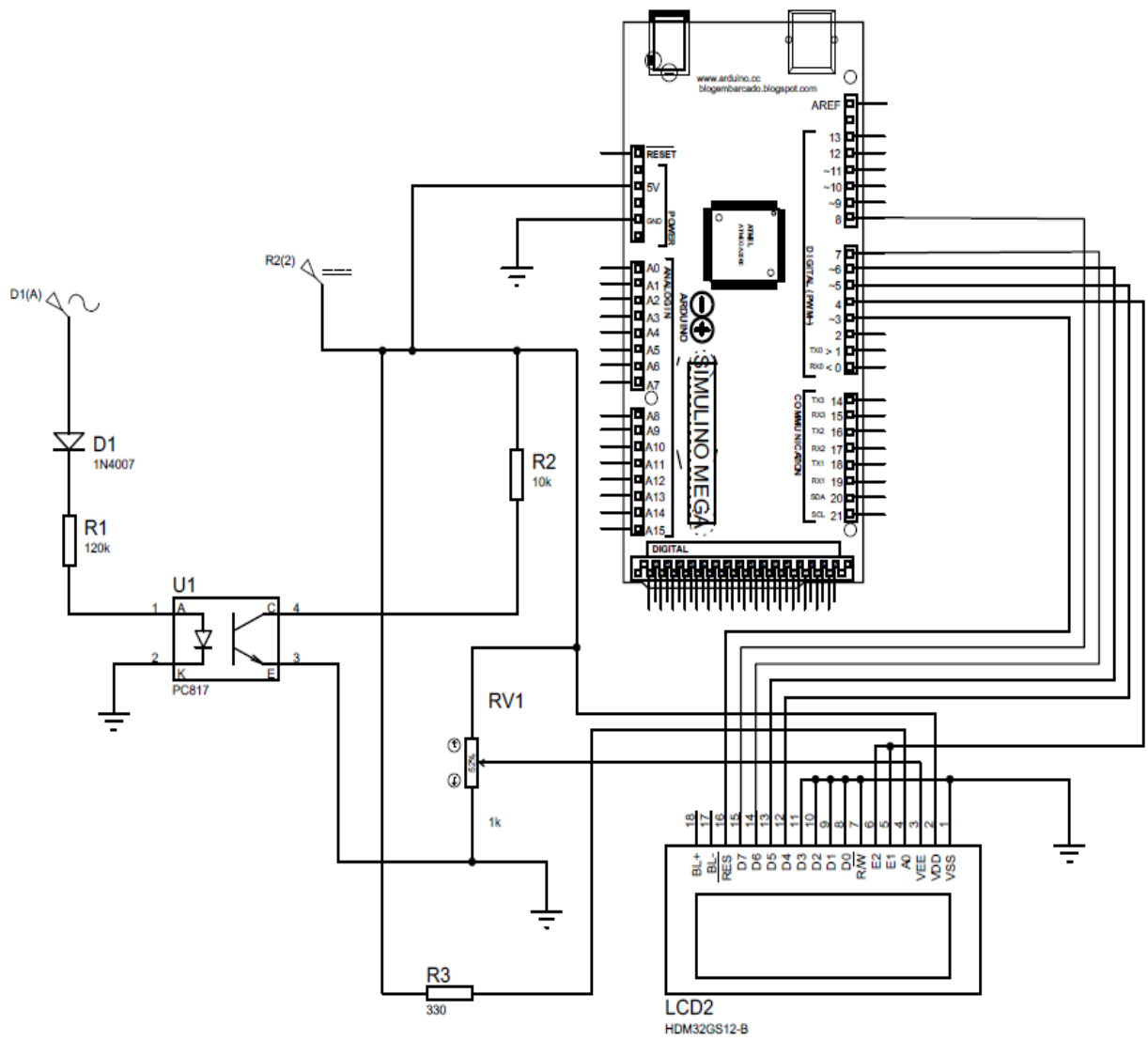

Figure 7. Frequency meter circuit using arduino 


\subsection{Phase angle circuit}

As explained before in section 2.4 and as shown in Figure 8 the phase angle circuit mainly depends on multiplayer IC (AD633j). We use voltage dividends to reduce the voltage and connect them directly to the multiplier, so we have two sinusoidal waves with different phase angles. The output of this circuit is connected to Arduino circuit and the Arduino sends the signal to power switches to connect the output of DFIG to the Grid.

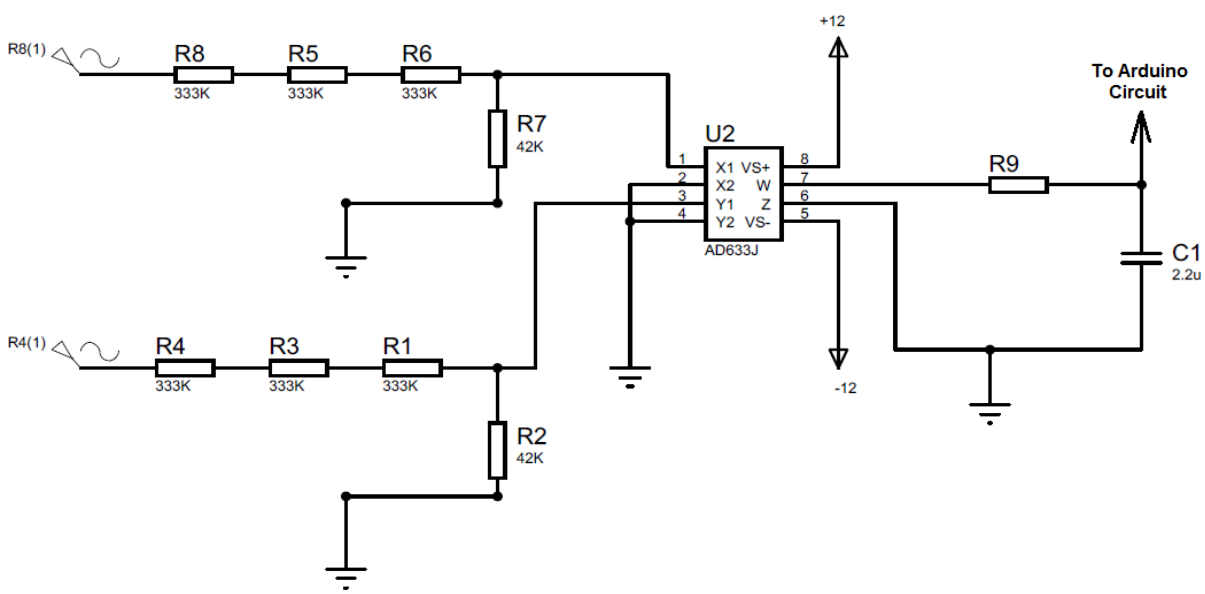

Figure 8. Multiplayer circuit

\subsection{Experimental results} as follows:

The results can be presented in three stages; voltage comparator, frequency meter and phase detector

\subsubsection{Voltage comparator}

As shown in Figure 9, the measured AC voltages (XMM3, XMM4) for DFIG and the grid are different, so the measured DC voltage is different (XMM1, XMM2) and there is no output from the AND gate; LED3 is OFF.

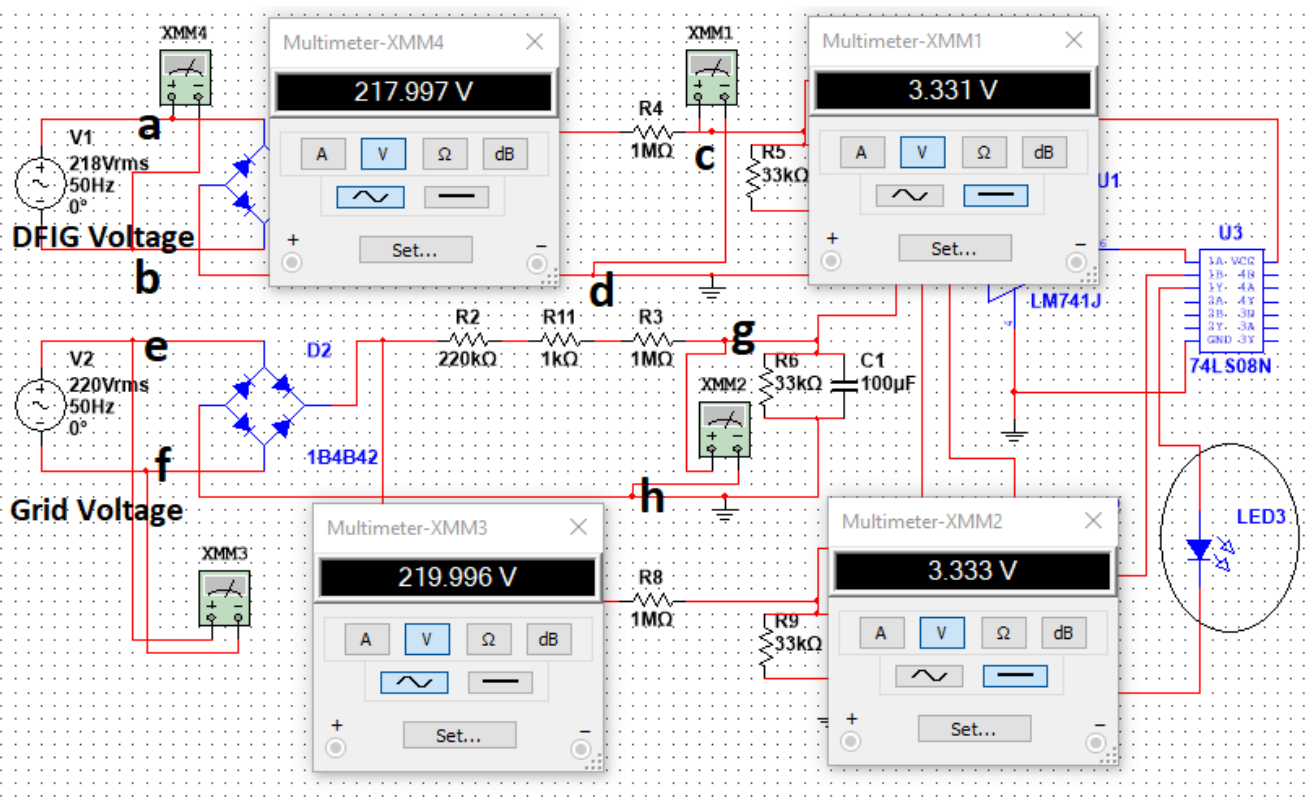

Figure 9. Voltage comparator circuit 
When the measured AC voltages (XMM3, XMM4) and DC voltages (XMM1, XMM2) are equal, the AND gate output is energized; LED3 is ON as shown in Figure 10.

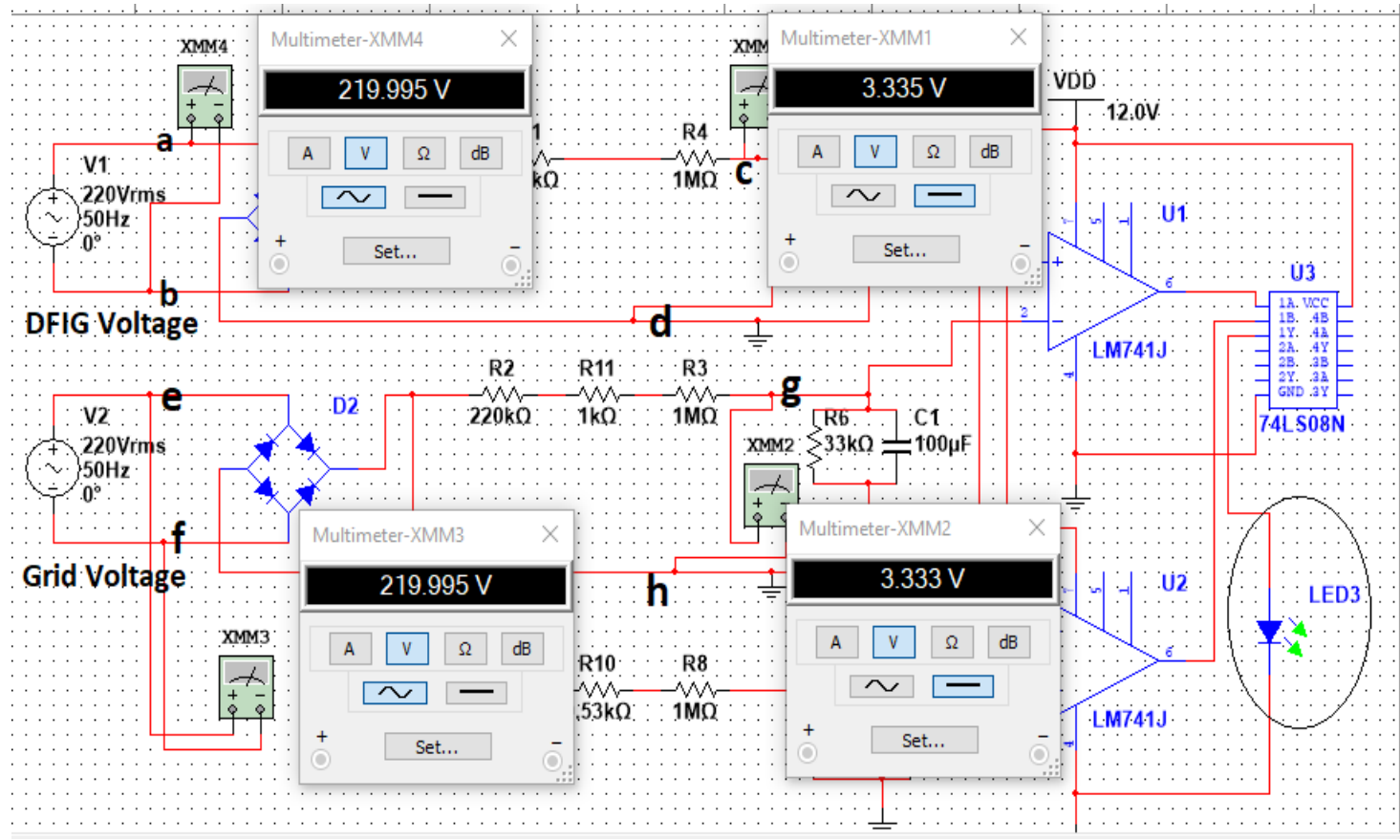

Figure 10. Voltage comparator circuit

\subsubsection{Frequency meter}

The result of the implemented frequency meter is shown in Figure 11.

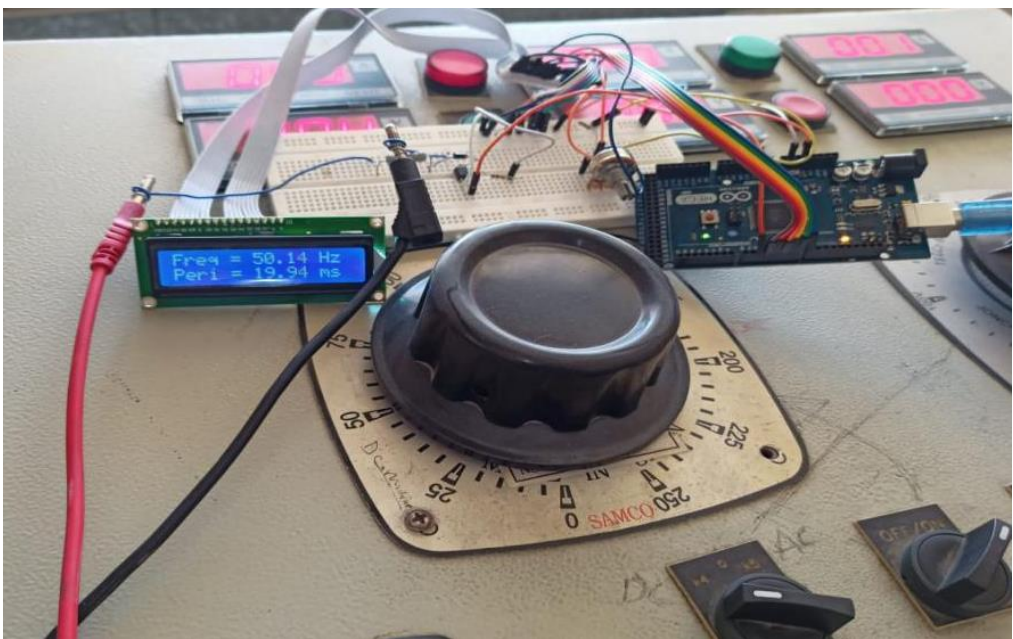

Figure 11. Frequency meter circuit using arduino phase

\subsubsection{Phase difference detector}

As shown in Figure 12 we have two sinusoidal signals; one from the grid and the other from DFIG with different phase angles. The circuit output varies from -3.9 and +3.9 VDC. The Arduino as we explained before takes the action of connecting the DFIG to the Grid when the circuit output single equals zero. 


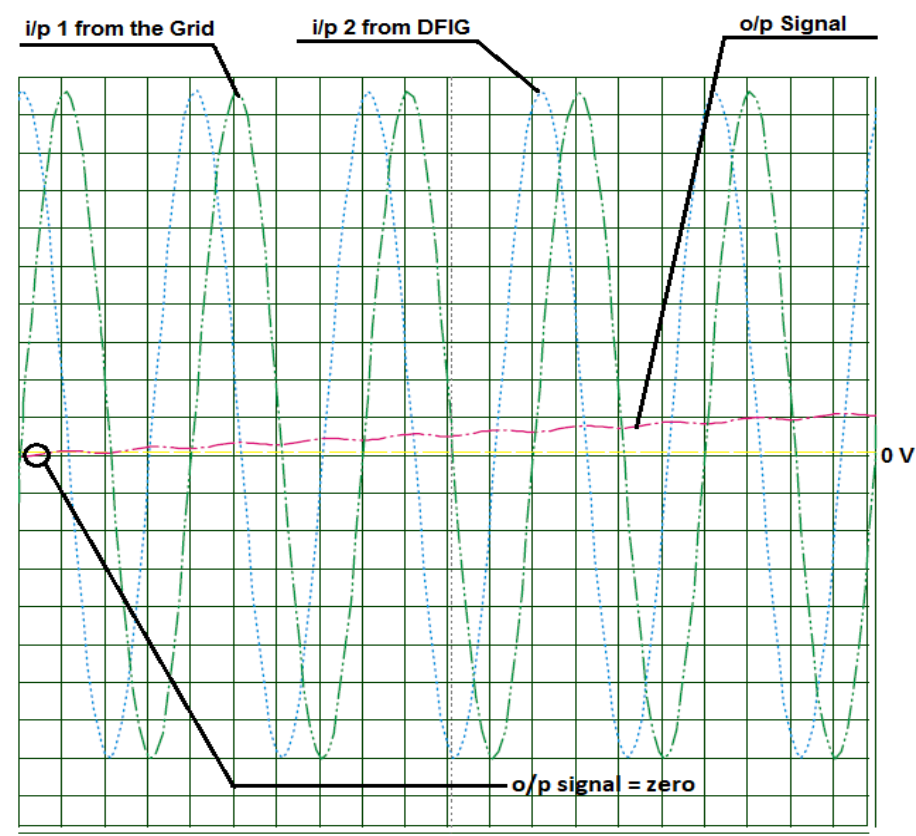

Figure 12. Input and output signals for multiplier (AD633j)

\section{CONCLUSION}

Control circuits for interfacing a DFIG with the Grid have been designed, implemented and laboratory examined. The detailed description of the electronic circuits that have been used are presented and discussed. These circuits provide phase sequence detection, voltage level comparison, frequency metering and synchronization. These implemented circuits offer the feature of real time monitoring the DFIG output frequency. These circuits have been implemented with the Arduino kit in addition to some logic circuits. 0.05 to $0.05 \mathrm{~V}$ is the dynamic range of the system phase comparison. A salient feature of these circuits is the possibility of synchronizing any type of two different generators. They have been designed for attenuation factor of $-16.5 \mathrm{~dB}$ to reduce the voltage to be interfaced with the logic circuits. The frequency meter circuit has been designed, implemented and successfully experimental tested. It can be even used for any signal frequency measurements. The results show many system features such as reliability, simplicity and practical suitability.

\section{ACKNOWLEDGEMENTS}

We thank Assistant Professor El-sayed Soliman A. Said for his great effort for designing and operating electrical circuits inside and outside the laboratory.

\section{REFERENCES}

[1] M. F. Zohra, B. Mokhtar, and M. Benyounes, "Sliding mode performance controlapplied to a DFIG system for a wind energyproduction," International Journal of Electrical and Computer Engineering (IJECE), vol. 10, no. 6, pp. 6139-6152, 2020.

[2] S. Hlaing, "Basic Concepts of Doubly Fed Induction Generator Driven by Wind Energy Conversion System," International Journal of Scientific Engineering and Technology Research, vol. 03, no. 15, pp. 3242-3246, 2014.

[3] S. M. M. Deicke and R. W. De Doncker, "Doubly Fed Induction Generator for Wind Turbine a viable Alternative to Adjust Speed Over a Wide Range at Minimal Cost," IEEE Industry Applications Magazine, 2002.

[4] A. Ramkumar, "Performance Analysis of Doubly Fed Induction Generator Based Wind Energy Conversion Systems," Department of Electrical and Electronics Engineering Kalasalingam University, India, Jun. 2014.

[5] Y. Djeriri, A. Meroufel, A. Massoum, and Z. Boudjema, "Direct Power Control of A Doubly Fed Induction Generator Based Wind Energy Conversion Systems Including A Storage Unit," Journal of Electrical Engineering, vol. 14, pp. 196-204, Mar. 2014.

[6] J. Arbi et al., "Direct Virtual Torque Control for Doubly Fed Induction Generator Grid Connection," IEEE Transactions on Industrial Electronics, vol. 56, no. 10, pp. 4163-4173, Oct. 2009.

[7] S. Chandrasekaran, "Grid Connected Doubly Fed Induction Generator Based Wind Turbine under LVRT," Department of Electric, Electronic and Information Engineering, University of Bologna, Italy, 2014. 
[8] B. Rabelo and W. Hofmann, "Power Flow Optimisation and Grid Integration of Wind Turbines with the DoublyFed Induction Generator," IEEE 36th Power Electronics Specialists Conference, 2005, pp. 2930-2936.

[9] H. Benbouhenni, "Comparison study between seven-level SVPWM and two-level SVPWM strategy in direct vector control of a DFIG-based wind energy conversion systems," International Journal of Applied Power Engineering (IJAPE), vol. 9, no. 1, pp. 12-21, Apr. 2020.

[10] R. D. Shukla and R. K. Tripathi, "Speed-sensorless Voltage \& Frequency Control in Autonomous DFIG based Wind Energy Systems," Australasian Universities Power Engineering Conference, AUPEC 2014, Curtin University, Perth, Australia, 2014.

[11] R. Dhanuka, "Modelling of Doubly Fed Induction Generator Based Wind Turbine," National Institute of Technology, Rourkela Odisha, India, May 2013.

[12] S. N. Singh, J. Østergaard, and B. Singh, "Reactive Power Capability of Unified DFIG for Wind Power Generation," IEEE PES General Meeting, Providence, RI, 2010, pp. 1-7.

[13] Petersson A., "Analysis, Modeling and Control of Doubly-Fed Induction Generators for wind Turbines," Phd Thesis, Chalmers University of Technology, Göteborg, Sweden, 2005.

[14] A. Ghasemi, M. H. Refan, and P. Amiri, "Enhancing the performance of grid synchronization in DFIG-based wind turbine under unbalanced grid conditions," Springer-Verlag GmbH Germany, part of Springer Nature, 2020.

[15] Ş. Demirbaş and S. Bayhan, "Grid Synchronization of Doubly Fed Induction Generator in Wind Power Systems," International Conference on Power Engineering, Energy and Electrical Drives, Torremolinos (Málaga), Spain, May 2011.

[16] J. L. Da Silva et al., "A Discussion about a Start-up Procedure of a Doubly-Fed Induction Generator System," NORPIE/2008, Nordic Workshop on Power and Industrial Electronics, Jun. 2008.

[17] S. Z. Chen et al., "Grid Synchronization of Doubly-fed Induction Generator Using Integral Variable Structure Control," IEEE Transactions on Energy Conversion, vol. 24, no. 4, Dec. 2009.

[18] A. Khan et al., "Doubly Fed Induction Generator Open Stator Synchronized Control during Unbalanced Grid Voltage Condition," MDPI, Rourkela Odisha, Energies, vol. 13, p. 3155, 2020.

[19] A. G. Abo-Khalil et al., "Grid Connection of Doubly-Fed Induction Generators in Wind Energy Conversion System," IEEE 5th International Power Electronics and Motion Control Conference, Shanghai, China, 2006.

[20] G. Yuan, J. Chai, and Y. Li., "Vector Control and Synchronization of Doubly Fed Induction Wind Generator System," IEEE 4th International Power Electronics and Motion Control Conference, pp. 886-890, 2004.

[21] A. G. Abo-Khalil, "Synchronization of DFIG Output Voltage to Utility Gridin wind power system," Renewable Energy, vol. 44, pp. 193-198, 2012.

[22] X. Zhang, D. Xu, Y. Lang, and H. Ma, "Study on Stagewise Control of Connecting DFIG to the Grid," IEEE 5th International Power Electronics and Motion Control Conference, pp. 1-5, 2006.

[23] S. A. Gomez and J. Amenedo, "Grid synchronization of doubly fed induction generators using direct torque control," IEEE 28th Annual Conference of the Industrial Electronics Society, pp. 3338-3343, 2002.

[24] P. Brown, M. Evans, D. Hunt, and D. Mathews, "The calculus of trigonometric functions-A guide for teachers," in J. Pitkethly, Education Services Publishers, Australia, Module 15, 2011- 2012.

[25] Analog Devices Data sheet, "Low Cost Analog Multiplier AD633." 